\title{
Cell cycle-dependent expression of CXC chemokine receptor 3 by endothelial cells mediates angiostatic activity
}

\author{
Paola Romagnani, ${ }^{1}$ Francesco Annunziato, ${ }^{2}$ Laura Lasagni, ${ }^{1}$ Elena Lazzeri, ${ }^{2}$ \\ Chiara Beltrame, ${ }^{2}$ Michela Francalanci, ${ }^{1}$ Mariagrazia Uguccioni, ${ }^{3}$ Grazia Galli, ${ }^{2}$ \\ Lorenzo Cosmi, ${ }^{2}$ Lucia Maurenzig, ${ }^{1}$ Marco Baggiolini, ${ }^{3}$ Enrico Maggi, ${ }^{2}$ \\ Sergio Romagnani, ${ }^{2}$ and Mario Serio ${ }^{1}$
}

${ }^{1}$ Department of Clinical Pathophysiology, Endocrinology Unit, and

${ }^{2}$ Department of Internal Medicine, Clinical Immunology and Allergy Unit, University of Florence, Florence, Italy

${ }^{3}$ Theodor Kocher Institute, University of Bern, Bern, Switzerland

Address correspondence to: Paola Romagnani, Department of Clinical Pathophysiology,

Endocrinology Unit, University of Florence, Viale Pieraccini 6, 50139, Florence, Italy.

Phone: 0039-055-4271365; Fax: 0039-055-4271371; E-mail: promagnani@iol.it.

Received for publication March 3, 2000, and accepted in revised form November 16, 2000.

\begin{abstract}
Endothelial cell receptors for the angiostatic chemokines IFN- $\gamma$-inducible protein of $10 \mathrm{kDa}$ (IP-10) and monokine induced by IFN- $\gamma(\mathrm{Mig})$ have not yet been identified, and the mechanisms responsible for the effects of these chemokines on angiogenesis are still unclear. IP-10 and Mig share a common functional receptor on activated $\mathrm{T}$ lymphocytes, named CXC chemokine receptor 3 (CXCR3). Using in situ hybridization and immunohistochemistry, we show that CXCR3 is expressed by a small percentage of microvascular endothelial cells in several human normal and pathological tissues. Primary cultures of human microvascular endothelial cells (HMVECs) likewise express CXCR3, although this expression is limited to the S/G2-M phase of their cell cycle. Both IP-10 and Mig, as well as the IFN- $\gamma$-inducible T-cell $\alpha$ chemoattractant (I-TAC), which all share high-affinity binding for CXCR3, block HMVEC proliferation in vitro, an effect that can be inhibited by an anti-CXCR3 antibody. These data provide definitive evidence of CXCR 3 expression by HMVEC and open new avenues for therapeutic interventions in all conditions in which an angiostatic effect may be beneficial.
\end{abstract}

J. Clin. Invest. 107:53-63 (2001).

\section{Introduction}

Angiogenesis is an important event occurring in a number of physiological and pathological processes such as embryonic development, wound healing, chronic inflammation, and the growth of malignant solid tumors (1). The rate of normal capillary endothelial cell turnover in adults is typically measurable in months or years (2). However, during wound repair, resting endothelial cells undergo activation that leads to matrix proteolysis, migration, proliferation, and development of new capillaries in a strictly controlled and transient way, depending on the levels of angiogenic and angiostatic mediators expressed in the wounded tissue (3). In contrast to the precise regulation of wound-associated angiogenesis, tumor angiogenesis is characterized by an imbalance that favors the overexpression of angiogenic factors and the underexpression of angiostatic substances $(4,5)$. Several factors involved in angiogenesis are known, and the activity of some of them is presently being tested in clinical trials (6). Among factors involved in angiogenesis, a number of chemokines have been found to exhibit disparate effects (7).

Chemokines are a family of small proinflammatory peptides, mainly known because of their chemotactic activity on leukocytes (8-10), which can be divided into major families, based on the position of the first two cysteine amino acid residues in the molecule (8-10). There are at least four families of chemokines, but only two have been extensively characterized (8-10). In general, CXC chemokines attract neutrophils and lymphocytes, whereas chemokines belonging to the CC family act primarily on monocytes, but they can also attract lymphocytes, basophils, and eosinophils (8-10). Several lines of evidence indicate that CXC chemokines are involved in the control of angiogenesis (7-9). In general, members of the CXC chemokine family that display binding and activation of neutrophils share the capacity to induce angiogenic responses both in vitro and in vivo, whereas CXC chemokines that do not bind to neutrophils mainly act as potent angiostatic factors. This difference has been attributed to the presence or absence of the ELR motif in the amino acid sequence (11). However, this possibility is unlikely, as stromal derived factor- $1 \alpha$ (SDF-1), a non-ELR CXC chemokine, also exhibits angiogenic activity (12).

Despite a large series of studies, the nature of receptors responsible for the angiostatic activity of some chemokines is still controversial. IP-10 and platelet factor 4 (PF4), which are able to inhibit endothelial cell proliferation in culture by inducing a reversible growth arrest (13), share a cell-surface binding site on endothe- 
lial cells that appears to be a heparan sulfate proteoglycan (HSPG), inasmuch as their binding can be inhibited by pretreatment with either heparitinase or trypsin (13). The binding to HSPG is an important component of the angiogenic activity of several endothelial growth factors, such as bFGF, VEGF, and IL-8 (14). Since PF4 can specifically replace bFGF on its specific endothelial cell binding sites (15), it is possible that a competitive mechanism accounts for the angiostatic effects of nonELR chemokines. Recently, however, PF4 was identified as an inducer of cell synchronization (16), which acts independently of its binding to HSPG and induces a signal transduction, thus suggesting the existence of a not yet identified specific receptor (17). Angiostatic effects have been described in vivo for both IP-10 and Mig, which share a common functional receptor on activated $\mathrm{T}$ lymphocytes, named $\mathrm{CXC}$ chemokine receptor 3 (CXCR3) (18). Among $\mathrm{T}$ lymphocytes, CXCR3 expression has been shown to be higher on Th1 cells (19). Another chemokine, 6Ckine, was recently found to interact with CXCR3 and to exert angiostatic activity in mice (20). However, the same chemokine does not bind CXCR3 in humans (21).

On the basis of these data, we hypothesized that CXCR3 could account for the angiostatic and antitumor activity elicited by IP-10 and Mig both in vitro and in vivo (7). The results of this study provide definitive evidence that CXCR3 is expressed by microvascular endothelial cells in several human normal and pathological tissues. Furthermore, we found that primary cultures of human microvascular endothelial cells (HMVECs) express CXCR3 when they enter the S/G2-M phase of their cell cycle. More importantly, we demonstrated that not only IP-10, but also Mig and I-TAC, which share high-affinity binding to CXCR3, acted as effective inhibitors of endothelial cell proliferation. Last, the inhibitory effect of IP-10, Mig, and I-TAC on the proliferation of HMVEC was blocked by the addition in culture of an anti-CXCR3 $\mathrm{mAb}$. These results represent the first example of a chemokine receptor strictly associated to a cell-cycle phase and suggest that this receptor is directly involved in the control of endothelial cell proliferation, thus providing a convincing explanation for the angiostatic activity $(7,11,13)$ of IP-10 and Mig.

\section{Methods}

Reagents. Two anti-CXCR3 mAb's were used throughout the study. One (IgG1, clone 49801.111) was purchased from R\&D Systems Inc. (Minneapolis, Minnesota, USA), and the other (IgG1, clone 1C6) (22) was obtained from Millennium Pharmaceuticals Inc. (Boston, Massachusetts, USA). The anti-vWF rabbit polyclonal antibody was purchased from DAKO A/S (Glostrup, Denmark). Anti-cyclin A and anti-cyclin B1 rabbit polyclonal antibodies were purchased from Santa Cruz Biotechnology Inc. (Santa Cruz, California, USA). Phycoerythrin -conjugated (PE-conjugated) goat anti-rabbit and isotype control antibodies were pur- chased from Southern Biotechnology Associates (Birmingham, Alabama, USA). Peroxidase-conjugated antimouse IgG rabbit antibody and saponin were purchased from Sigma Chemical Co. (St. Louis, Missouri, USA). Human recombinant IP-10, Mig, I-TAC, SDF-1 $\alpha$, TGF- $\beta 1$, and bFGF were purchased from Peprotech Inc. (Rocky Hill, New Jersey, USA).

Tissues. Specimens from normal human kidneys and from their neoplastic counterparts were obtained from five patients undergoing nephrectomy because of localized renal tumors and from biopsies of three patients suffering from glomerulonephritis. Gut specimens were obtained from normal gut tissue of three patients undergoing colectomy because of localized primitive colon cancer and from inflamed tissue of four patients undergoing colectomy for Crohn's disease or ulcerative colitis. Liver specimens were obtained from normal organs of two patients undergoing hepatectomy because of metastatic cancer and from pathological tissue of two patients explanted because of active cirrhosis. Human thyroid specimens were obtained from normal tissue of patients undergoing thyroidectomy for localized primitive thyroid cancer and from pathological tissue obtained from three patients with Graves' disease. Normal human thymuses were obtained from three children undergoing corrective cardiac surgery because of congenital abnormalities. The procedures used in this study were in accordance with the regional ethical committee on human experimentation.

Immunohistochemistry. Immunohistochemical staining was performed on $10-\mu \mathrm{m}$ cryostat sections or cultured cells fixed in $4 \%$ paraformaldehyde at room temperature for 20 minutes. Sections were subsequently exposed to $0.03 \%$ hydrogen-peroxidemethanol solution to quench the endogenous peroxidase activity. After 30 minutes of preincubation with normal horse serum (Vectastain ABC kit; Vector Laboratories, Burlingame, California, USA), sections were layered for 30 minutes with anti-human CXCR3 mAb (49801.111, $0.5 \mu \mathrm{g} / \mathrm{ml}$, and 1C6, 0.5-1.0 $\mu \mathrm{g} / \mathrm{ml}$ ), followed by biotinylated anti-mouse IgG horse antibody, and the avidin-biotin-peroxidase complex (Vectastain ABC kit), as described elsewhere (23). As a peroxidase substrate, 3-amino-9-ethyl-carbazole (AEC; Sigma Chemical Co.) was used. Finally, sections were counterstained with Gill's hematoxylin (Merck, Darmstadt, Germany). All incubations were performed at room temperature. As negative control, the primary $\mathrm{mAb}$ was omitted or replaced with an isotype control-matched $\mathrm{mAb}$ with irrelevant specificity.

In some experiments, CXCR3 and vWF were colocalized on the same sections by double staining immunohistochemistry, according to the method detailed elsewhere (23). Briefly, after 30 minutes' preincubation with normal horse serum (Vectastain ABC kit), sections were layered for 30 minutes with anti-human CXCR3 $\mathrm{mAb}$, followed by biotinylated anti-mouse IgG horse antibody, the avidin-biotin-peroxidase complex (Vectastain ABC kit), and AEC (red) as peroxidase substrate. 
Sections were subsequently exposed to anti-vWF polyclonal antibody (DAKO A/S) and Vector SG (bluishgray) was used as a chromogen. No counterstain was applied. Colocalization of AEC and Vector SG in the same cell resulted in a final purple-brown color.

RT-PCR. RT-PCR was performed using the specific oligonucleotides already described by Feil and Augustin (24). The CXCR3 sense primer was 5'-CCACTGCCAATACAACTTCC, whereas the antisense primer was $5^{\prime}$-GCAAGAGCAGCATCCACATC. RT-PCR was performed using a commercially available kit (GeneAmp RNA PCR; Roche Molecular Biochemicals, Mannheim, Germany), according to the manufacturer's instructions. One microgram of total RNA was reverse-transcribed with an oligo dT16 primer in the presence of MuLV RT. The resulting cDNA was amplified using a 480 Thermal cycler from Perkin Elmer-Cetus (Norwalk, Connecticut, USA) as follows: first 5 minutes at $94^{\circ} \mathrm{C}$ for denaturation, followed by 1 minute at $94^{\circ} \mathrm{C}, 1$ minute at $55^{\circ} \mathrm{C}, 1$ minute at $72^{\circ} \mathrm{C}$ for 40 cycles. The last cycle was terminated with 7 minutes at $72^{\circ} \mathrm{C}$. Primers for $\beta$-actin were used to normalize the results. The antisense primer was $5^{\prime}$-CTGGTGCCTGGGGCG, and the sense primer was $5^{\prime}$-AGCCTCGCCTTTGCCGA as described previously (25).

Cloning and sequencing of CXCR3 probe. mRNA was extracted from human thymus, reversed to first-strand cDNA and amplified by RT-PCR technique, as described earlier here. The DNA fragment of $401 \mathrm{bp}$ amplified by PCR was subcloned in PGEM-T (Promega Corp., Madison, Wisconsin, USA), according to manufacturer's instructions. Sequencing of the amplified product was performed by the dideoxynucleotide chain-termination method by using ${ }^{35} \mathrm{~S}$-dATP and sequenase enzyme (USB, Cleveland, Ohio).

In situ bybridization. In situ hybridization was performed on frozen sections by using CXCR3 RNA probe, as described previously (23). Briefly, the CXCR3 cDNA probe was subcloned in PGEM-4Z, and the plasmid was linearized with Hind III and Bam HI restriction enzymes, followed by phenol-chloroform extraction and ethanol precipitation. Thereafter, sense and antisense RNA probes were synthesized by using SP6 or T7 RNA polymerases in the presence of ${ }^{35} \mathrm{~S} \alpha$-thio-UTP. Frozen sections were mounted onto gelatin-coated slides and fixed with $4 \%$ paraformaldehyde for 20 minutes at room temperature. Sections were subsequently treated with $0.2 \mathrm{~N} \mathrm{HCl}$, pronase, glycine, and $4 \%$ paraformaldehyde for 20 minutes and then acetylated. Thirty microliters of hybridization solution containing $8 \times 10^{5} \mathrm{cpm}$ of ${ }^{35} \mathrm{~S}$-labeled CXCR3 RNA probes were applied to each section and covered with parafilm. Hybridization was performed at $52^{\circ} \mathrm{C}$ for 16 hours. Sections were subsequently washed, and removal of the nonspecifically bound probe by RNAase digestion and autoradiography were performed.

Combined in situ hybridization and immunohistochemistry was performed according to a technique described previously (23). Briefly, after hybridization with the CXCR3 probe, RNAase digestion, and appro- priate washings, sections were stained with the antivWF mAb and then subjected to autoradiography, as already described here.

Western blotting. After cell lysis in a buffer containing $20 \mathrm{mM}$ Tris, $150 \mathrm{mM} \mathrm{NaCl}, 1 \mathrm{mM}$ phenylmethylsulfonylfluoride, and $0.25 \% \mathrm{NP}-40,50 \mu \mathrm{g}$ of protein were separated on $10 \%$ SDS-PAGE under nonreducing conditions and then electrotransferred to nitrocellulose membranes (Sigma Chemical Co.). Nonspecific protein binding was blocked by incubating the membranes with $1 \times$ TBS, $0.15 \%$ Tween 20 , overnight at $4{ }^{\circ} \mathrm{C}$. The blot was washed twice for 15 minutes with TBST and incubated with the anti-CXCR3 mAb (49801.111, 0.5 $\mu \mathrm{g} / \mathrm{ml}$ ) in TTBS containing $2.5 \%$ BSA) for 90 minutes at room temperature. After four 15-minute washings with TBST, peroxidase-conjugated anti-mouse IgG rabbit antibody was added for 1 hour at room temperature, and the blot was again washed four times for 15 minutes at room temperature. The detection of specific signal was performed using the ECL detection system (Amersham Pharmacia Biotech AB, Uppsala, Sweden), according to the manufacturer's instructions. Proteins were measured by the method of Bradford (Bio-Rad Laboratories Inc., Hercules, California, USA).

Cell cultures. Primary cultures of HMVECs were obtained from Cascade Biologics Inc. (Portland, Oregon, USA) and cultured in medium 131 (M131), supplemented with Microvascular Growth Supplement (Cascade Biologics). HMVECs were used between the fifth and the seventh passage. Cells were detached by using EDTA $20 \mathrm{mM}$ in PBS (pH 7.2).

PBMCs were obtained from normal donors by centrifugation of heparinized blood on Ficoll-Hypaque gradient and antigen-specific CD4+ short-term T-cell lines were generated from PBMC suspensions as described previously (26). Briefly, PBMCs were stimulated in RPMI medium containing 5\% autologous serum with streptokinase (SK; $100 \mathrm{U} / \mathrm{ml}$, Behring, L'Aquila, Italy) for 5 days. On day 6 , activated T cells were expanded in the presence of recombinant IL-2 (20 U/ml; Eurocetus, Milan, Italy), and on day 15, they were assessed for CXCR3 expression.

Cultures of human mesangial cells (HMCs) were obtained from macroscopically normal kidneys of patients with localized renal tumors undergoing nephrectomy, as described previously (27).

Flow cytometry. After saturation of nonspecific binding sites with total rabbit IgG, cells were incubated for 20 minutes on ice with specific or isotype control antibody. In the indirect staining, this step was followed by a second incubation on ice with an appropriate antiisotype conjugated antibody. Finally, cells were washed and analyzed on a FACScalibur cytofluorimeter using the CellQuest software (both, Becton Dickinson Immunocytometry Systems, San Jose, California, USA). In all cytofluorimetric analyses, a total of $10^{4}$ events for each sample were acquired.

Cell-cycle evaluation. Single-cell suspensions were prepared and washed with cold PBS with $0.1 \%$ sodium 


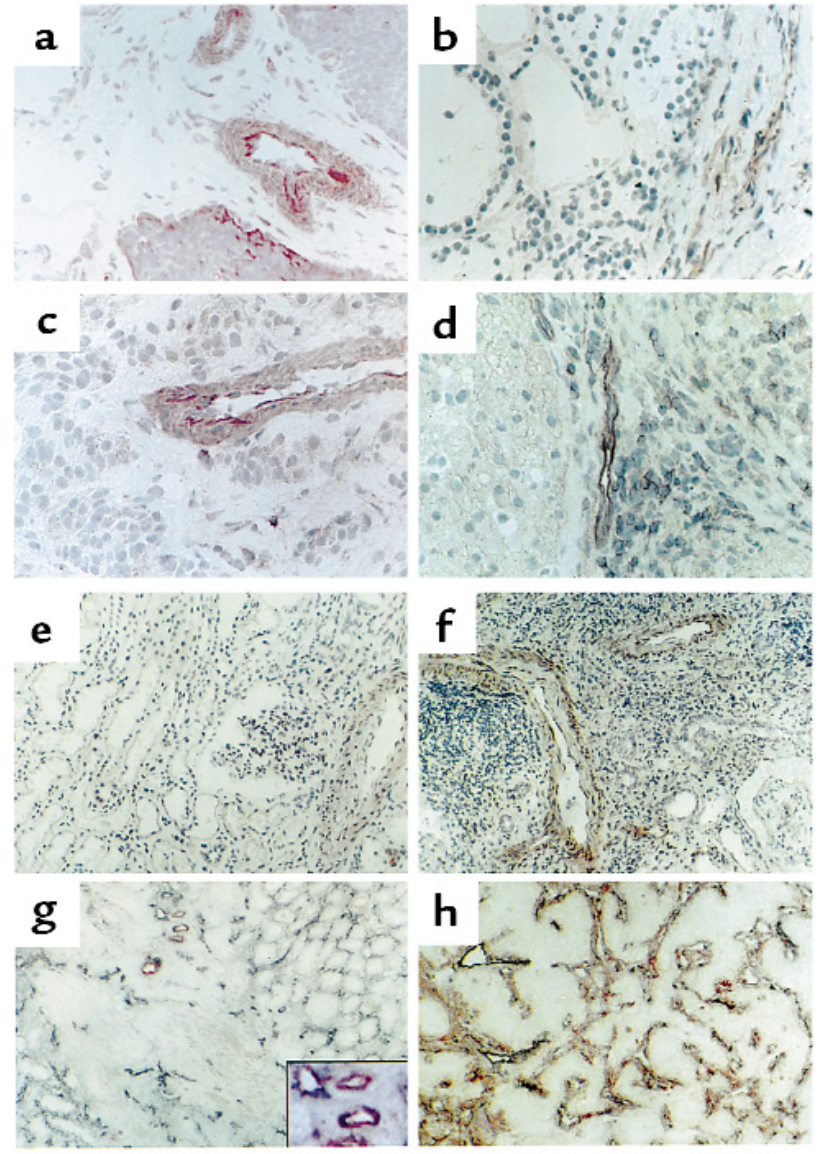

\section{Figure 1}

CXCR3 protein expression by a small proportion of microvascular endothelial cells in normal and pathological human tissues. (a) CXCR3 immunostaining (red) of endothelial and smooth muscle cells in a small arteriola of human thymus and in some thymocytes of the subcapsular areas. $\times 250$. (b) CXCR3 immunostaining (red) of endothelial cells in small vessels surrounding thyroid follicles in a biopsy specimen from a patient suffering from Graves' disease. $\times 250$. (c) CXCR3 expression (red) of endothelial and smooth muscle cells in an arteriola of normal liver. $\times 400$. (d) CXCR3 immunostaining (red) of endothelial cells from small vessels and of infiltrating inflammatory cells present in a biopsy specimen from a patient with active cirrhosis. $\times 250$. (e) CXCR3 expression (red) in a normal human kidney. Signal is clearly visible only at level of vascular smooth muscle cells. $\times 100$. (f) CXCR3 immunostaining (red) in the biopsy specimen of a patient suffering from glomerulonephritis. Signal is visible in both vascular smooth muscle cells and endothelial cells. $\times 100$. ( $\mathbf{g}$ and $\mathbf{h}$ ) Double-label immunohistochemistry for CXCR3 (red) and VWF (bluish-gray) showing CXCR3 expression by endothelial cells from some microvessels in the normal part of a human kidney $(\times 100)$ and from a much higher number of microvessels present in its neoplastic counterpart $(\times 100)$, respectively. Inset: Higher-power magnification of some microvessels in the normal part of the kidney. $\times 400$.

azide. Cells were then labeled with the FITC-conjugated anti-CXCR3 $\mathrm{mAb}$ in cold staining buffer, and after 30 minutes of incubation, they were washed once with staining buffer and once with PBS/azide alone. Cell pellets were gently resuspended and one part $(0.3 \mathrm{ml})$ of $50 \% \mathrm{FBS}$ in PBS was added. While gently mixing, three parts $(0.9 \mathrm{ml})$ of cold $70 \%$ ethanol in distilled water were added dropwise. Cells were then incubated for 2 hours at $4^{\circ} \mathrm{C}$ and then washed twice with cold PBS/azide to remove ethanol and precipitated protein. Propidium iodide was added at $50 \mu \mathrm{g} / \mathrm{ml}$ in PBS containing $100 \mathrm{U} / \mathrm{ml}$ RNAase. Cells were then incubated for at least 30 minutes at room temperature. Samples were acquired using a FACScalibur instrument and then analyzed with the Modfit LT software (Verity Software House Inc., Topsham, Maine, USA).

Intracytofluorimetric analysis of cyclin A and B1. After saturation of nonspecific binding sites with human $\operatorname{IgG}$, cell suspensions were incubated for 20 minutes at $4^{\circ} \mathrm{C}$ with FITC-conjugated anti-CXCR 3 or isotype control $\mathrm{mAb}$. Cells were then washed twice with PBS ( $\mathrm{pH}$ 7.2); fixed 15 minutes with formaldehyde (2\% in PBS [pH 7.2]); washed twice with $0.5 \%$ BSA in PBS (pH 7.2); permeabilized with PBS ( $\mathrm{pH} 7.2$ ) containing $0.5 \% \mathrm{BSA}$ and $0.5 \%$ saponin; and then incubated for 15 minutes with rabbit anti-cyclin $\mathrm{A}$, anti-cyclin $\mathrm{B} 1$, or isotype control antibodies. After incubation, cells were washed twice with PBS ( $\mathrm{pH} 7.2$ ) containing $0.5 \%$ BSA and $0.5 \%$ saponin, incubated for 15 minutes with PE-conjugated goat anti-rabbit antibody, washed again, and analyzed on a FACSCalibur cytofluorimeter using the CellQuest software. The area of positivity was determined using an isotype-matched $\mathrm{mAb}$. In all cytofluorimetric analyses, a total of $10^{4}$ events for each sample was acquired.

Chemotactic assay. The chemotactic assay was performed as described previously (28). Briefly, IP-10 (100 $\mathrm{nM}$ ) in RPMI 1640 containing $0.5 \%$ BSA or medium alone was added to the lower well of a transwell chamber $(3-\mu \mathrm{m}$ pore size, 12 wells; Corning-Costar Corp., Acton, Massachusetts, USA). Activated Th1 cells $\left(5 \times 10^{6}\right)$ were resuspended in the same buffer and loaded into the upper well in the presence of antiCXCR3 or isotype control $\mathrm{mAb}(10 \mu \mathrm{g} / \mathrm{ml})$. Cell migration was allowed to occur for 3 hours at $37^{\circ} \mathrm{C}$, and cells migrated to the lower chamber were harvested and counted by FACSCalibur. Cells that migrated in the presence of medium alone served as a negative control.

Cell proliferation assays. HMVECs were detached by EDTA $20 \mathrm{mM}(\mathrm{pH} 7.2)$ and plated $\left(4 \times 10^{3}\right.$ cells per well) on 96-well culture plates (Nunc; Life Technologies, Gaithersburg, Maryland, USA) in medium 131 (M131) containing 5\% FCS. After 24 hours, medium was replaced by M131 plus 5\% FCS containing human recombinant bFGF $(5 \mathrm{ng} / \mathrm{ml})$, or human recombinant IP-10, Mig, I-TAC, or SDF-1 $\alpha(10 \mathrm{pM}-1 \mu \mathrm{M})$, and cell proliferation was assessed after 24,48 , and 72 hours. To this end, cells were pulsed for additional eight 8 ours with $4 \mu \mathrm{Ci}\left[{ }^{3} \mathrm{H}\right]$ thymidine/ml (Amersham, Roosendal, The Netherlands), then frozen at $-80^{\circ} \mathrm{C}$, and finally collected on glass-fiber paper with an automatic cell harvester (Tomtec; Wallac, Oy, Tonko, Finland). Radioactivity of dry filters was measured by liquid scintillation spectroscopy (1205 Betaplate; Wallac). Experiments were independently repeated with three different primary HMVEC cultures. In some experiments, $1 \times 10^{4}$ cells were in parallel cultured in 24-well plates 
in the presence of bFGF $(5 \mathrm{ng} / \mathrm{ml})$ without or with different IP-10 concentrations, and after 72 hours, the number of viable cells was evaluated by using the trypan blue dye exclusion technique.

Statistical analysis. Statistical analysis was performed using Student's $t$ test for unpaired data considered significant at the level of $P<0.05$.

\section{Results}

Detection of CXCR3 on a small proportion of microvascular endothelial cells in human tissues. By using the 49801.111 anti-CXCR3 mAb, CXCR3 expression was detected on a small number of vascular wall cells of all normal tissue specimens examined, such as thymus (Figure 1a), liver (Figure 1c), kidney (Figure 1e), and thyroid and gut (data not shown), a higher signal being present over endothelial cells of patients with Graves' disease (Figure 1b) and in both endothelial and infiltrating inflammatory cells of the liver of patients with active cirrhosis (Figure 1d), as well as the kidney of patients with glomerulonephritis (Figure 1f). No staining was found in the same tissues by replacing the primary mAb with an isotype-matched control $\mathrm{mAb}$ with irrelevant specificity (data not shown). To provide direct evidence on the nature of cells expressing CXCR3 in vessels of normal or pathological tissues, double immunostaining with CXCR3 and vWF was performed. A few vessels in normal tissues, but higher percentages in corresponding inflamed tissues, showed positive CXCR3 staining. A semiquantitative evaluation of these differences is summarized in Table 1 . Of note, the highest propor- tions of CXCR3-positive vessels were found in some kidney tumors in comparison with their normal counterparts (Figure 1, g and h). When the 1C6 anti-CXCR3 mAb was used, very low or no signal was observed, except of some infiltrating lymphocytes in active inflammatory diseases and some thymocytes (data not shown). To exclude the possibility that CXCR3 expression on endothelial cells from normal or inflamed tissues was due to some undetermined artifactual effect, CXCR3 mRNA expression was also assessed by using in situ hybridization in the kidney of three patients with glomerulonephritis. CXCR3 mRNA was clearly present at the level of endothelial cells from some vessels, as also demonstrated by combining in situ hybridization for CXCR3 and immunohistochemistry for vWF (Figure 2).

CXCR3 $m R N A$ and protein expression by primary cultures of HMVECs. To provide additional evidence that CXCR3 could be expressed by HMVEC, primary cultures of these cells were assessed for CXCR3 expression at level of mRNA and protein by using RT-PCR and Western blotting, respectively. As positive controls, cultures of activated T lymphocytes showing a Th1-polarized profile of cytokine production $(18,19)$ and primary cultures of HMCs (27) were also tested. Both CXCR3 mRNA (Figure 3a) and protein (Figure 3b) were clearly visible in all the three types of cells, with remarkably higher expression by stimulated Th1 lymphocytes. Western blot analysis also demonstrated that all the three cell types expressed the same immunoreactive product (Figure $3 \mathrm{~b}$ ). The three cell types were then assessed for surface CXCR3 expression by flow cytome-
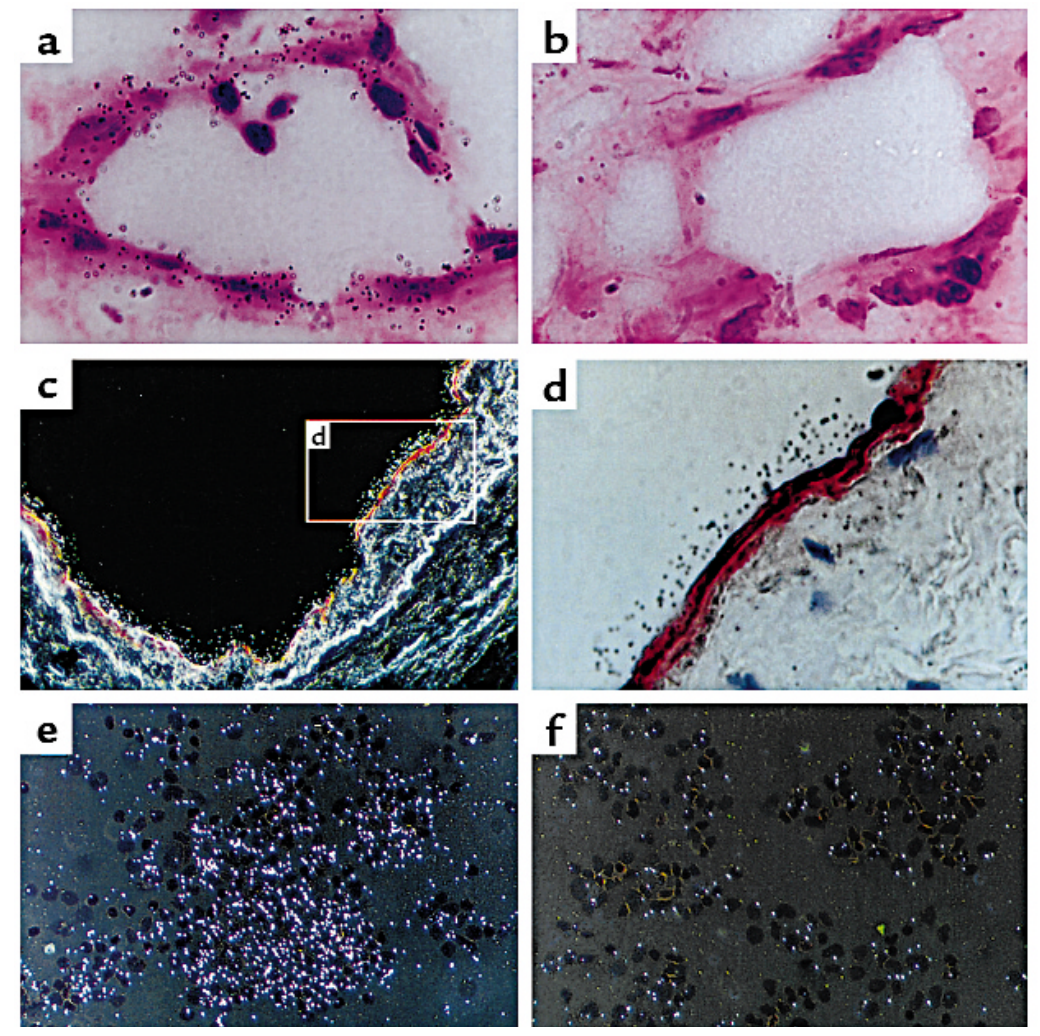

Figure 2

CXCR3 mRNA expression by endothelial cells from kidney of patients suffering from glomerulonephritis. (a) CXCR3 mRNA expression in the kidney biopsy specimen. The section, which was hybridized with ${ }^{35}$ S-labeled CXCR3 antisense probe, shows positive signal in a vessel wall. $\times 1,000$. (b) Autoradiograph of a consecutive section hybridized with sense CXCR3 probe, showing virtually no signal. $\times 1,000$. (c) Association between CXCR3 mRNA expression and VWF, as shown by combining in situ hybridization with CXCR3 antisense probe (white grains along the vessel wall) and immunohistochemistry with anti-vWF mAb (red) (dark field, $\times 250$ ). (d) Higher-power magnification $(\times 1,000)$ of inset in (c) showing both CXCR3 mRNA (black grains) and vWF expression (red). (e) CXCR3 mRNA expression by Th1 cells, used as positive control. The cells were hybridized with antisense CXCR3 probe (dark field, $\times 250$ ). (f) Autoradiograph of the same Th1 cell culture hybridized with sense CXCR3 probe, showing virtually no signal (dark field, $\times 250)$. 
Figure 3

CXCR3 mRNA and protein expression by primary cultures of HMVEC. (a) Total RNA from a Th1 clone, HMCs, and HMVECs was reverse transcribed and PCR amplified using CXCR3 (top) and $\beta$-actin (bottom) primers, as described in Methods. An aliquot of each PCR reaction was electrophoresed on $1.5 \%$ agarose gel and visualized with ethidium bromide. An incubation performed in the absence of RT is also shown (no RT). (b) Western blot analysis of extracts from activated Th1 cells, HMCs, and HMVECs. Cell lysates were separated on SDSPAGE under nonreducing conditions, transferred to nitrocellulose membranes, and assessed with the 49801.111 anti-CXCR3 mAb. (c) Flow cytometry of CXCR3 expression, evaluated with two different anti-CXCR3 mAb's (1C6, dashed line; 498011.111, solid line), on Th1 cells, HMCs, and HMVECs. The black peak represents staining of the same cells with the isotypematched control antibody. One of eight separate experiments for each technique is shown.

\section{a. CXCR3}

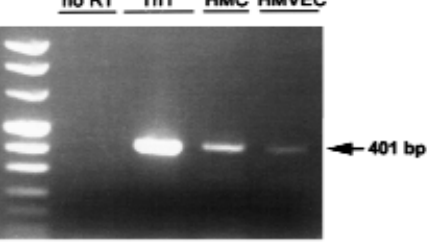

$\beta$-actin

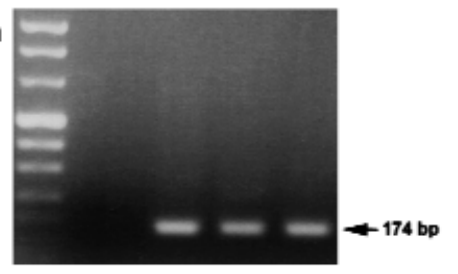

b

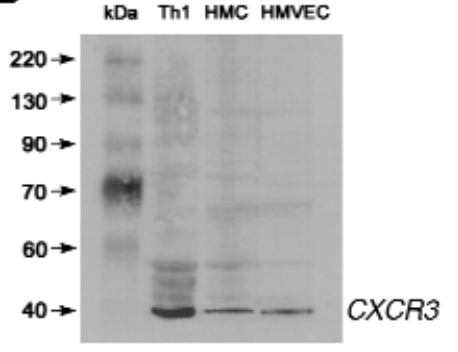

C

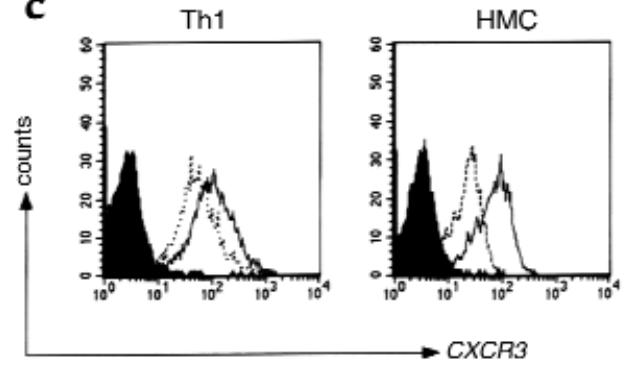

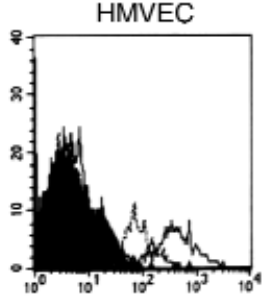

try by using the same two anti-CXCR3 mAb's, which had been used in the immunohistochemical analysis. Both anti-CXCR3 mAb's stained remarkable proportions of both Th1 cells (> 90\%) and HMCs (> 80\%), but smaller percentages (5-25\%) of HMVECs (Figure 3c). However, the mean fluorescence intensity of positively stained cells was consistently higher with 498011.111 than with the 1C6 mAb (Figure 3c). Taken together, these data suggest that even in vitro a small proportion

Table 1

Differential CXCR3 expression between endothelial cells from normal and pathological human tissues

\begin{tabular}{|c|c|c|}
\hline Tissue & CXCR3-positive vessels (\%) ${ }^{A}$ & $P$ \\
\hline \multicolumn{3}{|l|}{ Gut } \\
\hline Normal tissue & $1.5 \pm 1.2$ & \multirow{2}{*}{$<0.005$} \\
\hline Crohn's disease & $33.0 \pm 7.2$ & \\
\hline \multicolumn{3}{|l|}{ Thyroid } \\
\hline Normal tissue & $1.4 \pm 0.8$ & \multirow{2}{*}{$<0.005$} \\
\hline Graves' disease & $14.0 \pm 3.7$ & \\
\hline \multicolumn{3}{|l|}{ Liver } \\
\hline Normal tissue & $2.7 \pm 1.1$ & \multirow{2}{*}{$<0.001$} \\
\hline Cirrhosis & $23.7 \pm 6.8$ & \\
\hline \multicolumn{3}{|l|}{ Kidney } \\
\hline Normal tissue & $5.8 \pm 2.1$ & \multirow[b]{2}{*}{$<0.001$} \\
\hline $\begin{array}{l}\text { Glomerulonephritis } \\
\text { Primary tumors }\end{array}$ & $\begin{array}{l}16.4 \pm 4.8 \\
60.5 \pm 20\end{array}$ & \\
\hline
\end{tabular}

AVessels showing positive staining for vWF alone or vWF and CXCR3 were counted in five different fields (original magnification $\times 100$ ) of each normal or pathological tissue. Values represent mean percentages $( \pm S D)$ of vessels showing both VWF and CXCR3 staining in comparison with those showing staining for vWF alone. of HMVECs express CXCR3 and that this receptor is better detectable on their surface by using the 49801.111, rather than the 1C6, mAb.

Preferential expression of CXCR3 during the S/G2-M phase of endothelial cell cycle. To characterize the small population of CXCR3-positive HMVEC, an attempt was initially done to positively select this population by using the anti-CXCR3 mAb showing higher reactivity. However, despite repeated purification steps, when recultured for a few days, no more than 5-25\% of positively selected cells showed CXCR3 expression. Moreover, CXCR3 expression was observed on about $30-40 \%$ of cells that were far to be confluent and showed high proliferation rate, whereas no more than 5-10\% of confluent, growtharrested, HMVECs stained positive for CXCR3 (data not shown). These findings enabled us to hypothesize that CXCR3 expression by HMVECs was limited to a given phase of their cell cycle. To test this possibility, a double staining with FITC-conjugated anti-CXCR3 mAb and propidium iodide was performed on primary cultures of HMVECs, and the cells were then analyzed by flow cytometry. As shown in Figure 4, the highest DNA content, as revealed by propidium iodide levels, was found in CXCR3-positive cells, suggesting that these cells were in S/G2-M phase. Moreover, blocking HMVECs in G2$M$ phase by their treatment with nocodazole, a disrupter of microtubules, resulted in a remarkable increase in the number of CXCR3-expressing cells (Figure 5).

To support further the possibility that CXCR3 expression was mainly a property of cells in the S/G2-M phase of their cycle, HMVECs were synchronized in G0/G1 with contact inhibition and withdrawal of essential growth factors, whereas parallel cultures that were far to 


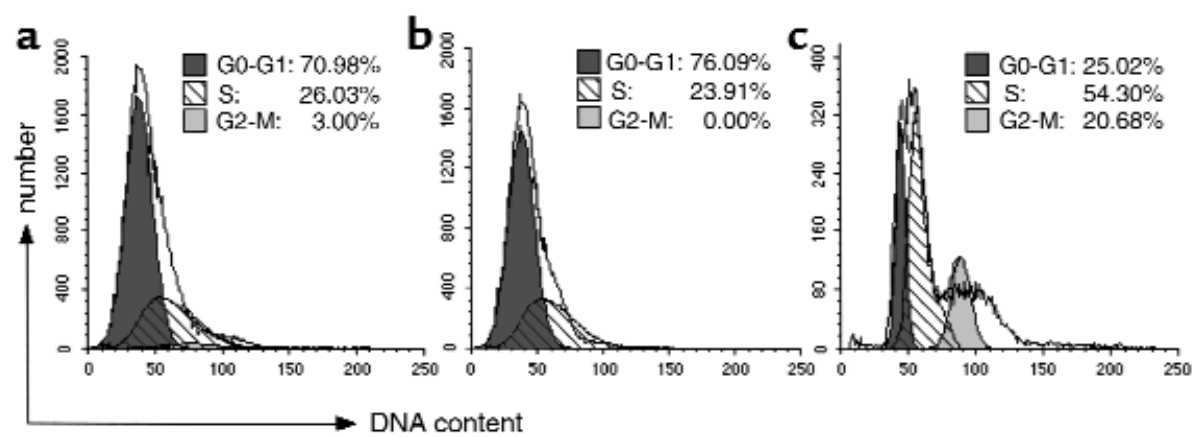

d

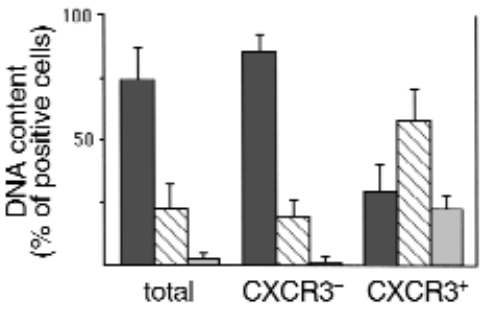

Figure 4

Prevalent CXCR3 expression by HMVECs in the S/G2-M phase of their cycle. Primary cultures of HMVECs, containing 20\% CXCR3-positive cells, were assessed for both CXCR3 expression and DNA content, as reported in Methods. Cell-cycle analysis was then performed by using the Modfit LT software on total (a), or gating on CXCR3-negative (b) or on CXCR3-positive (c), endothelial cells. One representative experiment is shown. (d) Columns represent mean values ( \pm SD) of HMVECs in G0-G1, S, and G2-M phase in total, CXCR3-negative, and CXCR3positive populations, obtained in four separate experiments.

be confluent, were stimulated with bFGF. Expression of CXCR3 and cyclin A (which is mainly detectable in the S/G2-M phase) was simultaneously assessed on both cell cultures. As control, expression of both CXCR3 and cyclin A was also evaluated on HMCs. As shown in Figure $6 \mathrm{a}$, cells synchronized in G0/G1 phase did not express CXCR3 or cyclin A. After bFGF stimulation, a remarkable proportion of cells expressed both cyclin A and CXCR3, whereas cyclin A-negative cells did not express CXCR3. By contrast, the presence of CXCR3 appeared to be independent from cyclin A expression in HMCs (Figure 6b). When the same HMVEC cultures were assessed for the simultaneous expression of CXCR3 and cyclin $\mathrm{B} 1$ (which is mainly detectable in the late $\mathrm{S}$ and the G2-M phase), virtually all cyclin B1-expressing cells also stained positively for CXCR3. Taken together, these data provide convincing evidence that CXCR3 expression by HMVECs is limited to the S/G2-M phase of their cell cycle.

Dose-dependent inbibition of HMVEC proliferation by IP-10, $\mathrm{Mig}$, and I-TAC, and blocking of their antiproliferative effect by anti-CXCR3 antibodies. Based on these findings, the possibility that IP-10 had an effect on the survival and/or growth of primary HMVECs via their interaction with CXCR3 selectively expressed during the phase of cell proliferation was investigated. To this end, HMVECs were seeded at low density in medium plus 5\% FCS, and 24 hours later they were incubated in new medium containing $5 \% \mathrm{FCS}$, without or with $\mathrm{bFGF}(5 \mathrm{ng} / \mathrm{ml})$, and in the presence of different concentrations of IP-10 (10 $\mathrm{pM}-1 \mu \mathrm{M})$. The addition of IP-10 induced a dramatic reduction of $\left[{ }^{3} \mathrm{H}\right]$ thymidine incorporation by both HMVECs kept in the presence of 5\% FCS and by cells stimulated with bFGF (Figure 7a). In some cultures, the inhibitory effect of IP-10 on DNA synthesis could be observed even at lower concentrations (Figure $7 \mathrm{~b}$ ). Moreover, IP-10 did not simply exert its inhibitory effect on DNA synthesis, but also affected cell proliferation, as shown by counting the number of viable cells found in parallel cultures after stimulation with bFGF in the absence or presence of different IP-10 concentrations
(Figure 7b). It is of note that IP-10 has been shown to have no inhibitory, but rather stimulatory, effect on the proliferation of HMCs (27), which express CXCR3 in a cycle-independent way (Figure 6b). The effect exerted on the bFGF-induced proliferation of HMVECs by Mig and I-TAC, another CXCR3-binding chemokine whose effect on angiogenesis is presently unknown, was also assessed. Both Mig and I-TAC also induced inhibition of endothelial cell proliferation, which was comparable
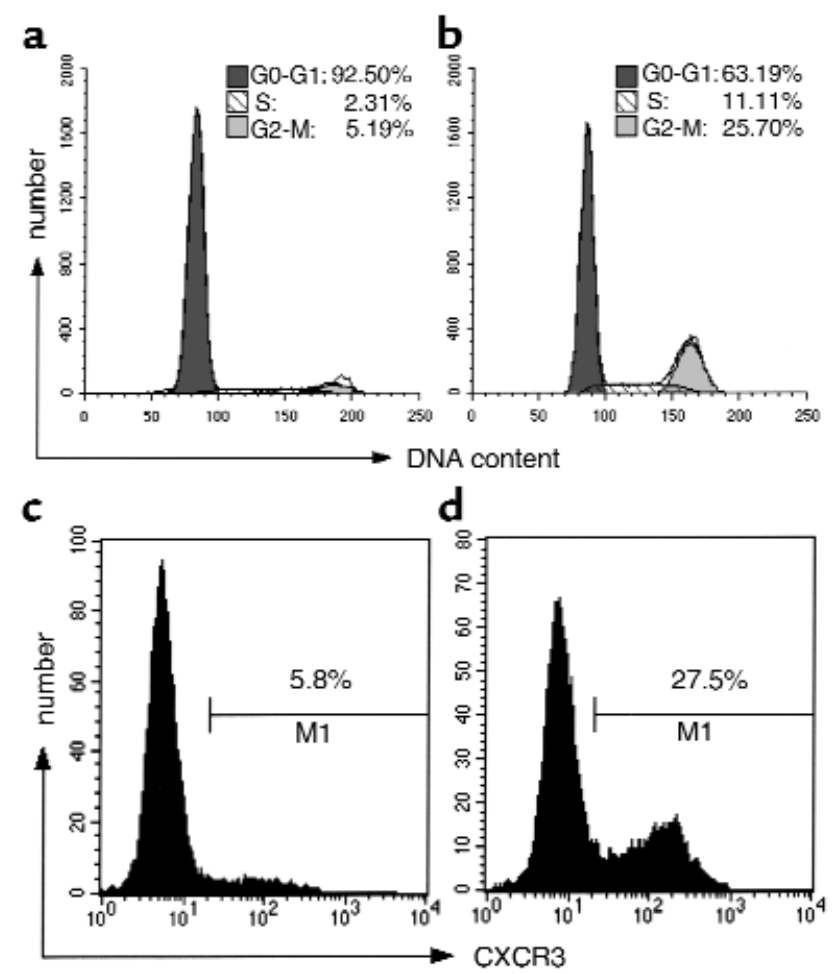

Figure 5

Increase in the number of CXCR3-expressing cells in HMVEC cultures treated with nocodazole. Primary cultures of HMVEC were incubated for 48 hours in the absence (a and $\mathbf{c}$ ) or presence (b and $\mathbf{d}$ ) of nocodazole (Sigma Chemical Co.) $(100 \mathrm{ng} / \mathrm{ml})$ and then assessed for both DNA content ( $\mathbf{a}$ and $\mathbf{b}$ ) and CXCR3 expression ( $\mathbf{c}$ and $\mathbf{d}$ ), as reported in Methods and in the legend to Figure 4. 

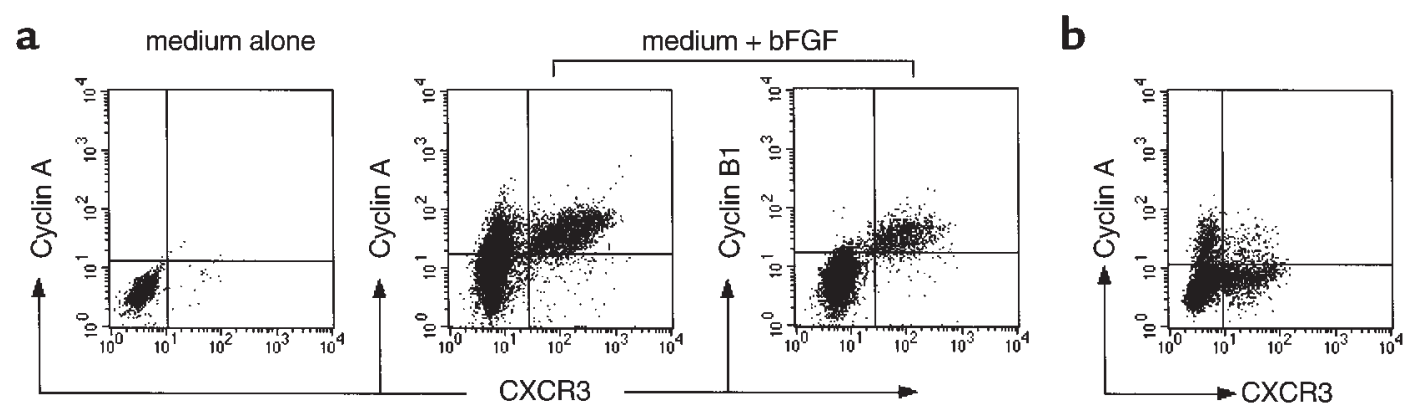

\section{Figure 6}

Association between CXCR3 and cyclin expression in HMVECs, but not in HMCs. HMVECs were synchronized in the G0-G1 phase of their cell cycle by contact inhibition and withdrawal of essential growth factors and then assessed for both CXCR3 and cyclin A expression (a, left). Parallel cell cultures that were not yet confluent were stimulated for 48 hours with bFGF and also assessed for CXCR3 and cyclin A (a, middle) or cyclin B1 (a, right) expression. HMCs stimulated under the same experimental conditions were also assessed at the same time for both CXCR3 and cyclin A expression (b). One representative of three separate experiments is shown.

to that exerted by IP-10 (Figure 7, $\mathrm{c}$ and d). By contrast, even high concentrations $(1 \mu \mathrm{M})$ of SDF- $1 \alpha$, another CXC chemokine, whose receptor, CXCR4, is highly expressed on endothelial cells $(28,29)$, and which shares with IP-10 and Mig the property to bind to HSPG (30), did not exert any inhibitory activity on cell proliferation (data not shown).

To provide definitive evidence that the inhibition of HMVEC proliferation induced by IP-10, Mig, and I-TAC was mediated by their interaction with CXCR3, the effect of anti-CXCR3 antibody on this phenomenon was assessed. The 49801.111 anti-CXCR3 $\mathrm{mAb}$, which was able to inhibit the chemotactic activity induced by IP-10 on activated human Th1 cells (Figure 8a), also significantly inhibited the antiproliferative activity induced on HMVEC by $100 \mathrm{nM}$ IP-10 (Figure 8b), although at $1 \mu \mathrm{M}$ chemokine concentration the difference in comparison with the isotype control antibody was not more statistically significant (Figure 8b). In subsequent experiments, we therefore compared the effect of anti-CXCR3 antibody on the antiproliferative activity induced on HMVEC by $100 \mathrm{nM} \mathrm{IP-10,} \mathrm{Mig,} \mathrm{and} \mathrm{I-TAC,} \mathrm{as} \mathrm{well} \mathrm{as} \mathrm{on}$ that induced by TGF- $\beta 1$, a CXCR3-unreactive cytokine. The anti-CXCR3 antibody also inhibited the antiproliferative activity of both Mig and I-TAC on HMVEC, whereas it did not affect the antiproliferative effect exerted on the same cells by TGF- $\beta 1$ (Figure 8c).

\section{Discussion}

Members of the CXC chemokine family are known to play an important role in the control of angiogenesis, that has been related to the expression of the sequence Glu-Leu-Arg (ELR) at their $\mathrm{NH}_{2}$ extremity (11). In general, ELR chemokines (IL-8, GRO- $\alpha$, ENA-78) bind to neutrophils and act as angiogenetic factors, whereas non-ELR chemokines (IP-10, Mig), which bind to lymphocytes, act as angiostatic factors (11). Recently, however, SDF-1, a CXC chemokine that lacks the ELR motif and is chemotactic for resting $T$ lymphocytes (8), has also been shown to possess angiogenic activity (29-31). The angiogenic activity of
SDF-1 is mediated by its interactions with CXCR4, which is highly expressed on endothelial cells (2931). Accordingly, CXCR4-deficient mice exhibit cardiovascular defects due to the lack of vascularization (32). The mechanisms that mediate the angiostatic effects of PF4, IP-10, and Mig are also still unclear (7, $11,13,33)$. A functional receptor for PF4 has not yet been described, but this chemokine, as well as IP-10, exhibits high affinity for an HSPG-binding site that is widely expressed on different cell types, including endothelial cells (13). Because these chemokines also share angiostatic activity, it has been hypothesized that PF4 and IP-10 exert their antiproliferative effects on endothelial cells via HSPG binding (13). Accordingly, endothelial cell growth factors such as bFGF, VEGF, or IL-8 enhance the ability to signal through their specific receptor binding site by using heparin or HSPG (14). Nevertheless, the inhibitory effect of PF4 on cell proliferation cannot be only dependent on HSPG, as this chemokine is also effective on EGFinduced endothelial cell proliferation, which does not require HSPG binding (16). Furthermore, PF4 interaction with endothelial cells induces a transduction signal through an unidentified receptor that upregulates the cytoplasmic levels of the regulatory cyclin p21 Cip1/WAF1 (17) and induces cell synchronization in the $S$ phase (16).

A potential receptor responsible for the activity of IP10 and Mig, CXCR3, has recently been cloned and characterized (18). However, despite the fact that IP-10 and Mig exert their activities on several cell types (27, 33-36), the expression of CXCR3 has initially been described only on activated $T$ lymphocytes, particularly those showing the Th1 phenotype of cytokine production $(19,22)$. More recently, CXCR3 mRNA has been detected by Northern blot analysis in several nonlymphoid tissues of normal mice, suggesting that the expression of this receptor is not T cell-specific (20). Accordingly, by using immunohistochemistry, we have observed high levels of CXCR 3 expression on activated HMCs, which were also induced by IP-10 and Mig to go 
into proliferation (27). Although detectable levels of CXCR3 mRNA have also been found in mouse endothelial cells (20), other reports have excluded the presence of this receptor on human umbilical vein endothelial cell (HUVEC) cultures $(29,30)$.

To overcome the problems related to the heterogeneity of HUVEC, as well as of other in vitro models of human cell cultures, in this study we have first assessed the expression of CXCR3 in human tissues by immunohistochemistry. Surprisingly, a small percentage of endothelial cells showed positive staining for CXCR3 in all tissues examined, which appeared to be mainly localized to endothelial cells of small vessels and was remarkably more frequent in inflamed and neoplastic than in normal tissues. This finding was confirmed at level of kidneys from patients with glomerulonephritis by demonstrating the presence of CXCR3 mRNA with in situ hybridization. Accordingly, when analyzed by RT-PCR and Western blotting, primary cultures of HMVECS showed both CXCR3 mRNA and protein expression, the immunoreactive product revealed by Western blotting being apparent- ly the same present in activated Th1 lymphocytes and HMCs. Finally, by using flow cytometry, percentages of cultured HMVECs comparable to those observed in vivo in inflamed tissues stained positively for CXCR3. Of note, in both immunohistochemical and cytofluorimetric analyses, the $1 \mathrm{C} 6$ anti-CXCR $3 \mathrm{mAb}$ appeared to be consistently less reactive than the 49801.111 anti-CXCR3 $\mathrm{mAb}$, although their antigen specificity was identical. This different sensitivity of the two antibodies might in part explain the difficulty to identify CXCR3 expression on endothelial cells, inasmuch as in the majority of studies the less reactive $1 \mathrm{C} 6 \mathrm{mAb}$ was used (22, 35-37). Very recently, however, CXCR3 expression by microvascular endothelial cells was also reported by another group (38).

The results of this study provide an additional and quite original explanation for the difficulty to detect CXCR3 expression on endothelial cells. We found indeed that these cells express CXCR3 only if they become activated and especially when they exhibit a high proliferation rate. More importantly, the simultaneous detection of both CXCR3 expression and cell
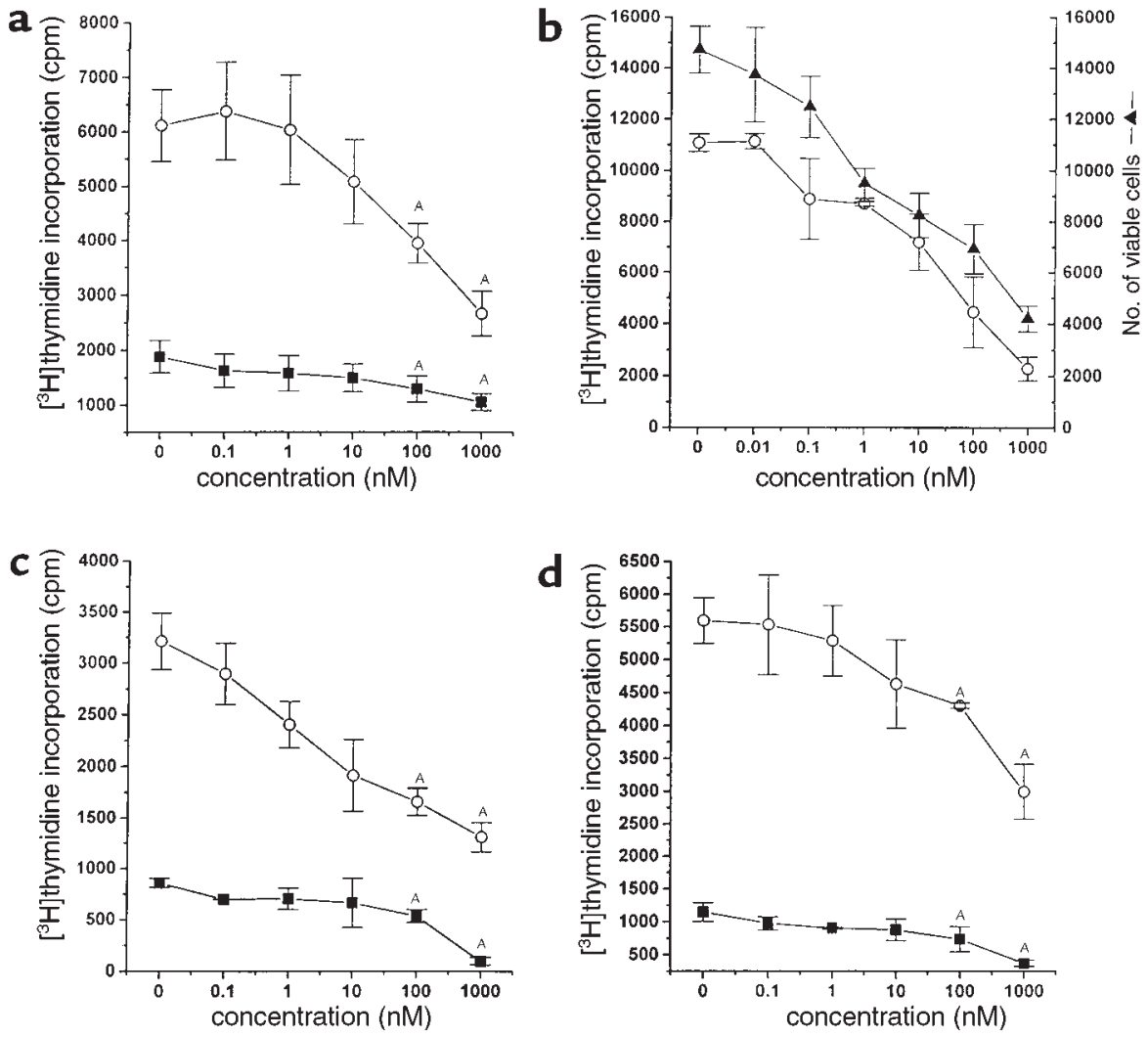

\section{Figure 7}

Inhibition of HMVEC proliferation by CXCR3-binding chemokines. After plating for 24 hours, HMVECs $\left(4 \times 10^{3}\right.$ per well) were cultured for 72 hours with different concentrations of IP-10, Mig, or I-TAC in the presence of medium alone (filled squares) or bFGF (5 ng/ml) (open circles), and 8 hours before harvesting cells were pulsed with $\left[{ }^{3} \mathrm{H}\right]$ thymidine $(4 \mu \mathrm{C} / \mathrm{ml})$. Results are expressed as mean values of counts per minute $( \pm$ SEM) obtained from triplicate cultures of four different experiments (a, $\mathbf{c}$, and $\mathbf{d})$. One representative experiment, in which both DNA synthesis (open circles) and number of viable cells (filled triangles) were assessed in parallel triplicate cultures stimulated with bFGF in the presence of different IP-10 concentrations, is also shown (b). Viable cells were counted by using the trypan blue dye exclusion technique. ${ }^{A} P<0.01$ 


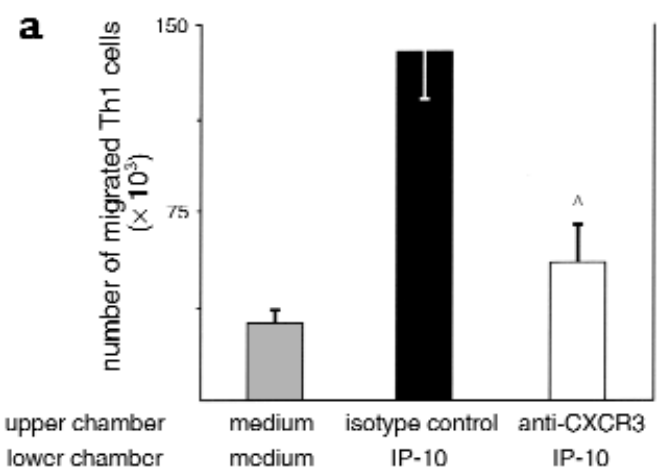

b
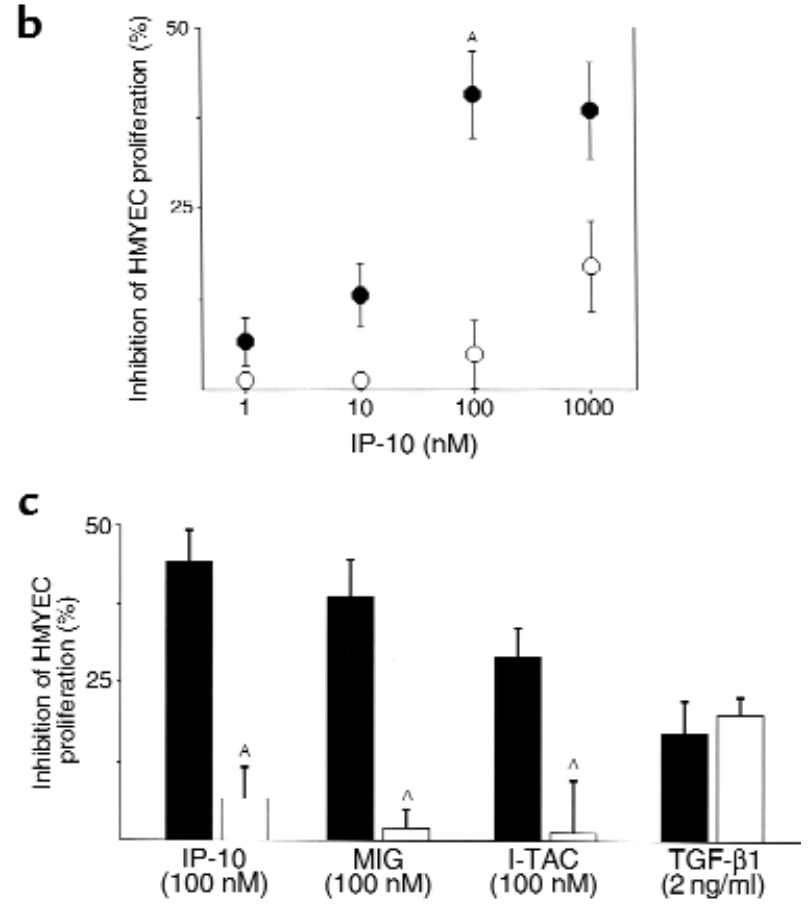

\section{Figure 8}

Inhibitory effect of anti-CXCR3 antibody on the antiproliferative activity induced by IP-10, Mig, and I-TAC on HMVECs. (a) Activated Th1 cells $\left(5 \times 10^{6}\right)$ were incubated with medium alone (shaded column) or IP-10 (100 nM) in the presence of anti-CXCR3 (open column) or isotype control (filled column), and migrated cells were counted by FACScalibur. Results are expressed as the mean numbers $( \pm$ SEM) of cells that migrated in response to medium alone or IP-10, obtained from triplicate cultures in three separate experiments. (b) HMVECs, after plating for 24 hours, were cultured $\left(4 \times 10^{3}\right.$ per well) for 72 hours with bFGF $(5 \mathrm{ng} / \mathrm{ml})$ plus different IP-10 concentrations in the presence of anti-CXCR3 (open circles) or isotype control (filled circles) mAb $(10 \mu \mathrm{g} / \mathrm{ml})$. Eight hours before harvesting, cells were pulsed with $\left[{ }^{3} \mathrm{H}\right]$ thymidine $(4 \mu \mathrm{Ci} / \mathrm{ml})$. Results are expressed as mean percent values ( \pm SEM) of inhibition of HMVEC proliferation obtained from triplicate cultures in three separate experiments. (c) HMVECs were cultured for 72 hours with bFGF $(5 \mathrm{ng} / \mathrm{ml})$ plus IP-10 (100 nM), or Mig (100 nM), or I-TAC (100 $\mathrm{nM})$, or TGF- $\beta 1(2 \mathrm{ng} / \mathrm{ml})$ in the presence of anti-CXCR3 (open column) or isotype control (filled column) mAb $(10 \mu \mathrm{g} / \mathrm{ml}$ ) and pulsed 8 hours before harvesting with $\left[{ }^{3} \mathrm{H}\right]$ thymidine (4 $\mu \mathrm{Ci} / \mathrm{ml}$ ). Results are expressed as mean percent values (+ SEM) of inhibition of HMVEC proliferation obtained in triplicate cultures in three separate experiments. ${ }^{A} P<0.05$. cycle evaluation clearly demonstrated that the great majority of CXCR3-positive cells were in the late S/G2-M phase of the cell cycle. First, DNA synthesis was much higher in CXCR3-positive than in the CXCR3-negative fraction of HMVEC. Moreover, the number of CXCR3-expressing cells was remarkably increased by the treatment of cells with nocodazole, a disrupter of microtubuli, which blocked a proportion of the cells into the G2-M phase of their cycle. Finally and more importantly, CXCR3 was absent from HMVECs synchronized in the G0/G1 phase, whereas it became clearly expressed by bFGF-stimulated HMVEC staining positively for cyclin A and selectively associated with cyclin B1-expressing cells. These data strongly suggest that CXCR3 is selectively expressed in the late $\mathrm{S}$ and in the G2-M phases of the endothelial cell cycle. By contrast, no association between CXCR3 and cyclin A expression in stimulated cultures of HMCs was observed.

The relationship between CXCR3 expression and the $\mathrm{S} / \mathrm{G} 2-\mathrm{M}$ phase of the endothelial cell cycle is of particular interest because this is the first chemokine receptor that appears to be expressed in association with a given cell-cycle phase. Moreover, this finding may provide a convincing explanation for the mechanisms involved in the angiostatic effects of CXCR3-binding chemokines. Luster et al. (13) described an IP10-mediated inhibition of endothelial cell proliferation that was independent of apoptosis, but dependent of cell-cycle arrest (13). In agreement with these findings, the results of our study clearly show that IP-10 was highly effective in inducing inhibition of endothelial cell proliferation. The effect started after 24 hours and became maximum after $48-72$ hours, in accordance with the length of the cell cycle, which was about 48-60 hours under the experimental conditions used. To explain the IP-10-mediated inhibition of endothelial cell proliferation, Luster and colleagues (13) hypothesized the role for a specific HSPG, perhaps leading to a competition between IP-10 and bFGF on HSPG binding. However, in this study we demonstrate that not only IP-10, but also Mig and I-TAC, the other two chemokines sharing the property to bind CXCR3 with high affinity, acted as effective inhibitors of endothelial cell proliferation. More importantly, the anti-CXCR3 49801.111 antibody significantly inhibited the antiproliferative effect of IP-10, Mig, and I-TAC on HMVECs. Of note, the 49801.111 anti-CXCR3 antibody, used at the same concentration $(10 \mu \mathrm{g} / \mathrm{ml})$, also inhibited the chemotactic activity induced by IP-10 on human activated Th1 cells (see Figure 8a), and it was found to completely block the GM-CSF-stimulated CD34+ progenitor chemotactic activity induced by both IP-10 and Mig (39), but it did not affect the antiproliferative effect of TGF- $\beta 1$, a cytokine that acts on the same cells by interacting with the TGF- $\beta$ type 2 receptor (40). Thus, the results of this study open new avenues for therapeutic interventions in all conditions in which an angiostatic effect may be beneficial. 


\section{Acknowledgments}

The experiments reported were supported by funds from Associazione Italiana per la Ricerca sul Cancro, from the University of Florence (Progetto Giovani Ricercatori), from the Ministero della Sanità (Programma per la ricerca finalizzata 1999 and 2000), and from Ministero dell'Università e della Ricerca Scientifica e Tecnologica.

1. Folkman, J. 1995. Angiogenesis in cancer, vascular, rheumatoid and other disease. Nat. Med. 1:27-31.

2. Tannock, I.F., and Hayashi, H.S. 1972. The proliferation of capillary and endothelial cells. Cancer Res. 32:77-82.

3. Leibovich, S.J., and Weisman, D.M. 1988. Macrophages, wound repair and angiogenesis. Prog. Clin. Biol. Res. 266:131-145.

4. Hanahan, D., and Folkman, J. 1996. Patterns and emerging mechanisms of the angiogenic switch during tumorigenesis. Cell. 86:353-364

5. Macchiarini, P., Fontanini, G., Hardin, M.J., Squartini, F., and Angeletti, C.A. 1992. Relation of neovascularization to metastasis of nonsmall cell lung cancer. Lancet. 340:145-146.

6. Belman, N., Bonnem, E.M., Harvey, H.A., and Lipton, A. 1996. Phase I trial of recombinant platelet factor 4 (rPF4) in patients with advanced colorectal carcinoma. Invest. New Drugs. 14:387-389.

7. Arenberg, D.A., et al. 1997. The role of CXC chemokines in the regulation of angiogenesis in non-small cell lung cancer. J. Leukoc. Biol. 62:554-562.

8. Baggiolini, M. 1998. Chemokines and leukocyte traffic. Nature. 392:565-568

9. Rollins, B.J. 1998. Chemokines. Blood. 90:909-928.

10. Zlotnik, A., and Yoshle, O. 2000. Chemokines: a new classification system and their role in immunity. Immunity. 12:121-127.

11. Strieter, R.M., et al. 1995. The functional role of the ELR motif in CXC chemokine mediated angiogenesis. J. Biol. Chem. 270:27348-27356.

12. Schnyder-Candryan, S., Srtieter, R.M., Kunkel, S.L., and Walz, A. 1995 Interferon- $\alpha$ and interferon- $\gamma$ downregulate the production of interleukin-8 and ENA-78 in human monocytes. J. Leukoc. Biol. 57:929-935.

13. Luster, A.D., Greenberg, S.M., and Leder, P. 1995. The IP-10 chemokine binds to a specific cell surface heparan sulfate shared with platelet factor 4 and inhibits endothelial cell proliferation. J. Exp. Med. 182:219-232

14. Yayon, A., Klagsburn, M., Esko, J.D., Leder, P., and Ornitz, D.M. 1991 Cell surface, heparin-like molecules are required for binding of basic fibroblast growth factor to its high affinity receptor. Cell. 64:841-848.

15. Sato, Y., Abe, M., and Takaki, R. 1990. Platelet factor 4 blocks the binding of fibroblast growth factor to the receptor and inhibits the spontaneous migration of vascular endothelial cells. Biochem. Biophys. Res. Commun. 172:595-600.

16. Gupta, S.K., and Singh, J.P. 1994. Inhibition of endothelial cell proliferation by platelet factor-4 involves a unique action on $S$ phase progression. J. Cell Biol. 127:1121-1127.

17. Gentilini, G., Kirschbaum, N.E., Augustine, J.A., Aster, R.H., and Visentin, G.P. 1999. Inhibition of human umbilical vein endothelial cell proliferation by the CXC chemokine, platelet factor 4 (PF4), is associated with impaired downregulation of p21(Cip1/WAF1). Blood. 93:25-33.

18. Loetscher, M., et al. 1996. Chemokine receptor specific for IP-10 and Mig: structure, function and expression in activated T-lymphocytes. J. Exp. Med. 184:963-969.

19. Bonecchi, R., et al. 1998. Differential expression of chemokine receptors and chemotactic responsiveness of type $1 \mathrm{~T}$ helper cells (Th1s) and Th2s. J. Exp. Med. 187:129-134.

20. Soto, H., et al. 1998. The CC chemokine 6Ckine binds the CXC chemokine receptor CXCR3. Proc. Natl. Acad. Sci. USA. 95:8205-8210.

21.Jenh, C.H., et al. 1999. Cutting edge: species specificity of the CC chemokine 6Ckine signaling through the $\mathrm{CXC}$ chemokine receptor CXCR3: human 6Ckine is not a ligand for the human or mouse CXCR3 receptors. J. Immunol. 162:3765-3769.

22. Qin, S., et al. 1998. The chemokine receptors CXCR3 and CCR5 mark subsets of $\mathrm{T}$ cells associated with certain inflammatory reactions. $J$. Clin. Invest. 101:746-754.

23. Romagnani, P., et al. 1998. High CD30 ligand expression by epithelial cells and Hassal's corpuscles in the medulla of human thymus. Blood. 91:3323-3332.

24. Feil, C., and Augustin, H.G. 1998. Endothelial cells differentially express functional CXC-chemokine receptor-4 (CXCR-4/fusin) under the control of autocrine activity and exogenous cytokines. Biochem. Biophys. Res. Commun. 247:38-45.

25. Kreuzer, K.A., et al. 1999. Highly sensitive and specific fluorescence reverse transcription-PCR assay for the pseudogene-free detection of beta-actin transcripts as quantitative reference. Clin. Chem. 45:297-300.

26. Maggi, E., et al. 1994. Ability of HIV-1 to promote a Th1 to Th0 shift and to replicate preferentially in Th2 and Th0 cells. Science. 265:244-248

27. Romagnani, P., et al. 1999. Role for interactions between IP-10/Mig and their receptor (CXCR3) in proliferative glomerulonephritis. J. Am. Soc. Nephrol. 10:2518-2526.

28. Annunziato F., et al. 2000. MDC and ELC attract human thymocytes in different stages of development and are produced by distinct subsets of medullary epithelial cells. Possible implications for negative selection. J. Immunol. 165:238-246.

29. Salcedo, R., et al. 1999. Vascular endothelial growth factor and basic fibroblast growth factor induce expression of CXCR4 on human endothelial cells. In vivo neovascularization induced by stromalderived factor-1 $\alpha$. Am. J. Pathol. 154:1125-1135.

30. Gupta, S.K., Ysko, P.G., Pillarisetti, K., Ohlstein, E., and Stadel, J.M. 1998. Chemokine receptors in human endothelial cells. Functional expression of CXCR4 and its transcriptional regulation by inflammatory cytokines. J. Biol. Chem. 273:4282-4287.

31. Amara, A., et al. 1999. Stromal cell-derived factor-1a associates with heparan sulfates through the first $\beta$-strand of the chemokine. J. Biol. Chem. 274:23916-23925.

32. Tachibana, K., et al. 1998. The chemokine receptor CXCR4 is essential for vascularization of the gastrointestinal tract. Nature. 393:591-594.

33. Angiolillo, A., et al. 1995. Human interferon-inducible protein 10 is a potent inhibitor of angiogenesis in vivo. J. Exp. Med. 182:155-162.

34. Wang, X., Lue, T.L., Ohlstein, E.H., Sung, C.P., and Fuerstein, G.Z. 1996. Interferon-inducible protein-10 involves vascular smooth muscle cell migration, proliferation, and inflammatory response. J. Biol. Chem. 271:24286-24293.

35. Trentin, L., et al. 1999. The chemokine receptor CXCR3 is expressed on malignant B cells and mediates chemotaxis. J. Clin. Invest. 104:115-121.

36. Rabin, R.L., et al. 1999. Chemokine receptor responses on T cells are achieved through regulation of both receptor expression and signaling. J. Immunol. 162:3840-3850.

37. Mach, F., et al. 1999. Differential expression of three T lymphocyteactivating CXC chemokines by human atheroma-associated cells. J. Clin. Invest. 104:1041-1050.

38. Salcedo, R., et al. 2000. Differential expression and responsiveness of chemokine receptors (CXCR1-3) by human microvascular endothelial cells and umbilical vein endothelial cells. FASEB J. 14:2055-2064.

39. Jinquan, T., et al. 2000. CXC chemokine receptor 3 expression on $\mathrm{CD} 34+$ hematopoietic progenitors from human cord blood induced by granulocyte-macrophage colony-stimulating factor: chemotaxis and adhesion induced by its ligands, interferon $\gamma$-inducible protein 10 and monokine induced by interferon $\gamma$. Blood. 96:1230-1238.

40. Sankar, S., et al. 1996. Modulation of transforming growth factor $\beta$ receptor levels on microvascular endothelial cells during in vitro angiogenesis. J. Clin. Invest. 97:1436-1446. 